Volume and Issues Obtainable at Center for Sustainability Research and Consultancy

Sustainable Business and Society in Emerging Economies

ISSN: 2708-2172 \& (E): 2708-2504

Volume 3: Issue 3 September 2021

Journal homepage: www.publishing.globalcsrc.org/sbsee

\title{
Exploring the nexus between Empowering Leadership and Work Engagement through Employee Resilience during times of Covid 19
}

Khawaja Khalid Mehmood, Institute of Management Sciences, Bahauddin Zakariya University, Multan, Pakistan

Shahbano Saeed, Institute of Management Sciences, Bahauddin Zakariya University, Multan,

Pakistan

*Corresponding author's email: shahbanosaeed980@gmail.com

\begin{tabular}{l}
\hline ARTICLE DETAILS \\
\hline History \\
Revised format: Aug 2021 \\
Available Online: Sep 2021 \\
\hline Keywords \\
Empowering Leadership, \\
Employee Resilience, \\
Psychological \\
Empowerment, \\
Work Engagement, \\
Private Schools of Pakistan.
\end{tabular}

JEL Classification

L20, M12

\section{ABSTRACT}

Purpose: Online learning system was adopted by private schools across Pakistan to lessen students' learning losses during the pandemic. It entailed the reliance on work from home model for their teaching staff. The success of these institutions must have been driven by a leadership style espoused by them which helped to keep their employees engaged. Thus, drawing on the job demand resource principle, conservation of resource principle, and broaden and build theory, this could be argued that empowering leadership may have engendered employee resilience which ultimately kept intact the work engagement of employees. Moreover, moderating impact of psychological empowerment has been studied to determine extent to which it might influence the employee resilience nurtured by empowering leadership.

Design/Methodology/Approach: Respondents for this study were faculty members of the private schools affiliated with the Multan board of Intermediate and Secondary Education Pakistan. Probability sampling was employed to select the schools and the faculty members of those schools were given questionnaires. The total responses obtained were 210. Structural equation modeling involving moderated mediation techniques was utilized to conduct analyses.

Findings: The study concluded that employee resilience mediated the association among empowering leadership and work engagement. However, the moderating effect was not proved.

Implications/Originality/Value: The study pays an original contribution to research by linking empowering leadership with employee resilience and work engagement for the faculty members during the time of Covid-19 Pandemic. It suggests schools' management to focus upon and reinforce empowering leadership for better work engagement of teachers. This would probably help them to retain students and sustain their performance. 


\section{(C) 2021 The authors, under a Creative Commons Attribution- NonCommercial 4.0}

Recommended citation: Mehmood, K. K. \& Saeed, S. (2021). Exploring the nexus between Empowering Leadership and Work Engagement through Employee Resilience during times of Covid 19. Sustainable Business and Society in Emerging Economies, 3(3), 375-387.

\section{Introduction}

The outbreak of the novel Corona Virus has precipitated a gigantic health crisis. It initially erupted in the Wuhan city of China but then quickly engulfed the world. WHO had to ultimately declare it a pandemic in March 2020 (Cucinotta \& Vanelli, 2020). It's a crippling disease that shocked the whole world to the core (Dhawan, 2020) and created unprecedented circumstances (Fernandez \& Shaw, 2020). However, in response to these horrendous circumstances, the health community worldwide devised a sensible plan to curb its spread. Social distancing seemed to be a fruitful strategy because it had been used in the past to combat the influenza virus (Ahmed, Zviedrite, \& Uzicanin, 2018).

Covid-19 catastrophe truly created a chaos which has terribly influenced every aspect of human life. When the medical community built a consensus over the usage of social distancing, the whole world apart from a few countries opted for a lock down to reduce the spread of the disease (Atalan, 2020). However, the radical measure didn't turn out to be a viable strategy because it landed the world in a financial crisis. The industrial sector worldwide is still trying to steer itself from a huge economic predicament that has had adverse impact on the lives of many people (Hart \& Halden, 2020).

Besides other sectors, the emergence of this disease also wreaked havoc in the education sector all over the world. The education institutions were also instantly closed to flatten the curve of the plague (Toquero, 2020). However, to continue the process of learning, online education system was adopted (Dhawan, 2020) which compelled the educational institutions to espouse the work from home model. Fortunately, many countries quickly shifted to the online mode of education which showed that the leadership and employees of these institutions intelligently navigated the challenges posed by the disease. It means that they would have adopted a right course of action which sustained the learning process in these distressing times. They must have gone for empowering leadership which has been proven to guarantee survival in turbulent times (Lee, Willis, \& Tian, 2018) and this leadership style should have been able to cultivate employee resilience which enabled their work force to persevere in these taxing conditions (Kuntz, Näswall, \& Malinen, 2016) like Pandemic. The leadership must have had fostered sufficient resilience which kept the employees engaged. Additionally, the employees must have felt enough psychological empowerment from inside which helped empowering leadership to successfully translate into employee resilience.

Different Scholars suggest that empowering leadership enhances job performance (Kundu, Kumar, \& Gahlawat, 2019). Similarly Employee resilience is considered to be a prerequisite for work engagement (Malik \& Garg, 2017). Work engagement considerably improves organizational performance and is a consequence of empowering leadership. Moreover, psychological empowerment is argued to have possible moderating impact for the association among empowering leadership and employee creativity (Özaralli, 2015).

Many studies did investigate an impact of empowering leadership on work engagement however no research has so far examined employee resilience as a crucial intervening variable between them. Additionally, only little studies have tried to probe the moderating effect of individual 
factors on the development of employee resilience and limited research has tried to discover psychological empowerment as a boundary condition. Hence, this study was carried out to determine the aforementioned relationships. Moreover, it obtained theoretical support from a couple of seasoned theories like Job demand resource principle (Bakker \& Demerouti, 2017), broaden and build theory (Fredrickson, 2001) and conservation of resource principle (Hobfoll, 2001). It's true that these theories have been abundantly used before in relation to these variables but they have never been employed to explain these particular relationships.

The study was organized in the private schools of South Punjab region of Pakistan which adopted the online education method to examine that how did they manage to navigate this crisis. Secondly, it tried to evaluate the success of the work from home model which was chosen by them to continue imparting education in these disturbing times. It's no brainer that until the employees have the capacity to brave a storm like pandemic then they may not be able to stay engrossed in their work. Thus employee resilience seems imperative to keep employees engaged. Hence, it's incumbent upon the leadership to instill this characteristic and its development has to be contingent on the level of empowerment felt from inside by an employee. If the employees get intimidated then the empowering leadership may not translate into employee resilience.

The rest of the paper is organized as follows. Section 2 presents the literature review containing the fundamental information on the variables involved as well as critical evaluation of past studies in the area. Section 3 delineates the methodology employed whereas section 4 explicates the results of the study in great detail. Lastly, section 5 encompasses an elaborated discussion on the results and also includes the implications, limitations, and future directions for the research.

\section{Literature Review and Hypotheses Development Empowering Leadership and Work Engagement}

Empowering leadership is a type of leadership which entails the leader to share power, delegate responsibility, and provide autonomy to followers which would eventually increase the intrinsic motivation of the followers (Özaralli, 2015). That's a holistic type of leadership consisting of three major leadership behaviors i.e. participative decision making, coaching and informing (Arnold, Arad, Rhoades, \& Drasgow, 2000). It's deemed as one of the best positive leadership styles that predict high employee career satisfaction (Kim \& Beehr, 2017), job crafting behaviors (Thun \& Bakker, 2018) and improves the mental balance of employees thereby leading to more employee positivity (Park, Kim, Yoon, \& Joo, 2017). Intellectuals have recommended the organizations to espouse this leadership style and throw of the shackles which cage their work force (Hu et al., 2018).

Work engagement can be understood as a productive and gratifying work related state of mind which comprises of vigor, absorption, and dedication (Schaufeli \& Bakker, 2004). Organizations are encouraged to increase work engagement because it elicits employee creativity (Hui et al., 2020) and increases their work related satisfaction (Lu, Lu, Gursoy, \& Neale, 2016). Many studies have shed light on the antecedents of work engagement. Different leadership styles such as transformational leadership (Breevaart \& Baker, 2018) have been identified as a potent predictor of engagement. Empowering leadership has also been found to influence work engagement via psychological empowerment (De Klerk \& Stander, 2014) and person job and group fit (Cai, Cai, Sun, \& Ma, 2018).

Job Demand and Resource theory (Bakker \& Demerouti, 2017) is used to explicate the development of work engagement. As per the theory, job characteristics could be divided into two categories i.e. Job demands and job resources. Job resources are those aspects in a job that are vital to the achievement of organizational goals and mitigate tensions associated with work. This theory has time and again posited job resources as paramount to development of work 
engagement. Additionally, empowering leadership is considered as an integral job resource (Støren, 2017) and also focuses on nurturing resources such as autonomy (Kim \& Beehr, 2020). Hence, drawing on the prior research and job demand resource principle, following hypothesis could be developed:

H1. Empowering leadership would positively impact work engagement.

\section{Empowering Leadership and Employee Resilience}

Employee resilience refers to an employee capability fostered by immense organizational support to constructively harness resources to intelligently adjust and survive in turbulent working environment (Kuntz et al., 2016). It has grabbed abundant attention because of the salutary effects that it guarantees. Highly resilient employees are very productive and courageously deal with any workplace challenges (Cooper, Wang, Bartram, \& Cooke, 2019).

Empowering leadership has also been recognized as one of the predictors of employee resilience (Nguyen, Kuntz, Näswall, \& Malinen, 2016). Additionally, Conservation of Resource theory (Hobfoll, 2001) also elucidates this relationship. This theory postulates that the human behavior is contingent on their capacity to procure and save resources which are essential to continue their lives in this world (Hobfoll, Halbesleben, Neveu, \& Westman, 2018). Besides the job resources, there are some psychological (personal) resources possessed by an employee to maintain a healthy state of mind and accomplish organizational goals (Schaufeli \& Taris, 2014). It further states that availability of certain resources can guarantee provision of other pivotal resources.

Employee resilience is frequently recognized as a crucial personal resource (Paek, Schuckert, Kim, \& Lee, 2015). Moreover, as stated above empowering leadership is one of the cardinal job resources. Thus, grounding on the conservation of resource theory, it can be presumed that employee resilience can be cultivated by using empowering leadership. Thus, following hypothesis could be conveniently proposed:

H2. Empowering leadership would positively impact employee resilience.

\section{Employee Resilience and Work Engagement}

Employee resilience is imperative to succeed because it enables the employees to accommodate in the dynamic circumstances (Franken, Plimmer, \& Malinen, 2020). It also alleviates tension amongst the team members (Meng, Jin, Guo, 2016). Moreover, it's found to engender work engagement because it's an important personal resource. A couple of studies have confirmed employee resilience as an antecedent of work engagement (Malik \& Garg, 2017; Turner, 2019). Additionally, Job demand and Resource theory (Bakker \& Demerouti, 2017) also supplies the theoretical underpinnings for the relationship because it categorically mentions that the job and personal resources foster work engagement when they outweigh the job demands. Since employee resilience is a personal resource so following is hypothesized:

H3. Employee resilience would positively impact work engagement.

\section{Empowering Leadership, Employee Resilience, and Work Engagement}

Prior researches have unveiled employee resilience as a consequence of empowering leadership (Kuntz et al., 2016) and a predictor of work engagement (Malik \& Garg, 2017). Thus, it's reasonable to assume that it may be an intervening construct between the two variables. Furthermore, its value as an important underlying mechanism can be derived from two very seasoned theories namely Broaden and Build theory (Fredrickson, 2001) and Conservation of Resource theory.

As per the conservation of resource (COR) theory, presence of one type of resource assures the availability of other resources so continuing on this idea, empowering leadership will augment 
employee resilience which would subsequently enhance work engagement. Moreover, broaden and build theory posits that healthy experiences elicit positive emotions which may augment different kinds of resources. Hence, empowering leadership may trigger employee resilience because it provides autonomy to employees. The employee resilience may ultimately bolster work engagement because it stimulates them to perform job related tasks better (Ojo, Fawehinmi \& Yusliza, 2021). Therefore, following mediation hypothesis is developed:

H4. Empowering leadership would impact work engagement of employees through employee resilience.

\section{Moderating Role of Psychological Empowerment}

Psychological (felt) empowerment can be understood as a mental state developed over time that is likely to nurture perceptions which include meaning, competence, self-determination, and impact (Spreitzer, 1995). It has been manifested as one of the outcomes of adopting empowering leadership style (Alotaibi, Amin, \& Winterton, 2020; Kundu et al., 2019). Moreover, it's recognized as a mediator between empowering leadership and work engagement (Qatrunnada \& Parahyanti, 2019). Although many researches have underscored its importance as a critical mediator but very few researches have probed its moderating effect. Recently, study of Özaralli (2015) investigated psychological empowerment's moderating impact for the association among empowering leadership and employee creativity. The findings corroborated its moderating effect and confirmed that degree to which empowering leadership may channelize creativity is dependent on the empowerment experienced by an employee.

In the same vein, it can be argued upon that it may also influence the development of employee resilience. It's likely that even if the organization adopts the empowering leadership style but employees may not feel empowered from inside which may ultimately obstruct the development of employee resilience. Furthermore, it is proposed to have an interaction effect with empowering leadership and ultimately affect employee resilience because previous researches have acknowledged the moderating effect of individual factors (like proactivity and optimism) over cultivation of employee resilience (Nguyen et al., 2016). Now, if the employee is too scared and lacks self-belief then there is a possibility that empowering leadership may not instill employee resilience which is crucial to development of work engagement in the face of the daunting crisis like Pandemic. Thus following hypothesis is developed:

H5. The relationship between empowering leadership and employee resilience is moderated by psychological empowerment.

Figure 1 illustrates various variables involved and the relationships proposed between them. Empowering leadership is the independent variable which is proposed to engender work engagement that is deemed as the dependent variable. Moreover, employee resilience is placed as an intervening variable which can be considered to be one of the critical underlying mechanisms by which empowering leadership might instigate work engagement. Furthermore, psychological empowerment is drawn as a moderating variable between empowering leadership and employee resilience which shows that like other individual characteristics it can also affect the development of employee resilience which will consequently influence work engagement. 


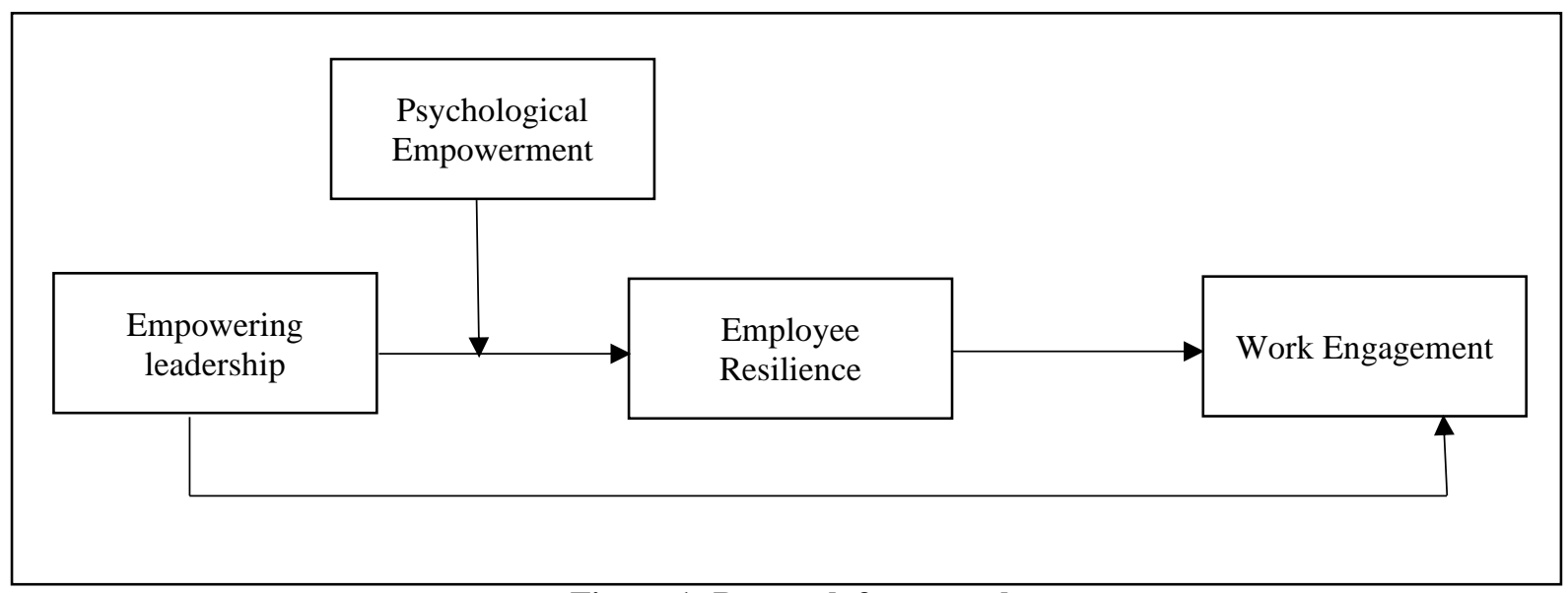

Figure 1: Research framework

\section{Research Methodology Sampling and Data Collection}

This research made use of quantitative research methodology. It was carried out in Pakistan's education sector wherein the data were collected from private schools affiliated with the Multan board of Intermediate and Secondary Education. The affiliated schools are based in Multan and the surrounding areas of the city. The total population of the schools was 566. Probability sampling technique was employed to draw a random sample of the private schools. Specifically, stratified sampling was used and two strata were made: one included private school based in Multan (228 schools), the other included schools operating outside Multan city (338). Systematic sampling was further used to draw a random sample from each strata.

Concerning sample size adequacy recommendations of Sekaran (2003) were followed according to which a study's sample must be greater than the total number of constructs in the study. In this research, there were four variables and since some were multi-dimensional, so in total there were 12 constructs; hence a sample of 120 or more was considered adequate. This study succeeded in securing responses from 220 respondents which was considered adequate. 113 responses were obtained from Multan based private schools and 107 responses from other schools operating outside Multan city. Ten questionnaires were discarded as they were substantially incomplete, so it left with 210 questionnaires for further analyses.

\section{Questionnaire Development}

The questionnaire for this study was developed using the scales from the previous studies and a 7 point Likert scale was utilized for the questions. For empowering leadership, the scale was adapted from the study of Ahearne, Mathieu, and Rapp (2005) which employed four dimensions for empowering leadership. These were 1. participation in decision making, 2. enhancing meaningfulness of work, 3. providing autonomy from bureaucratic constraints, and 4. expressing confidence in high performance. With each dimension having three items, empowering leadership was measured with 12 items. Work engagement was assessed using three dimensions (vigor, dedication, and absorption) and 12 items and the scale was adapted from Schaufeli, Bakker, and Salanova (2006). For employee resilience, scale from the study of Hodliffe (2014) was used that had 14 items. Finally, Spreitzer's (1995) scale was employed for measuring psychological empowerment. It had four dimensions (meaning, impact, competence, selfdetermination). Each dimension had three items, so psychological empowerment was assessed through 12 items. The items were adapted to suite the nature of industry and the respondents. 


\section{Analysis and Results of the Study}

The analysis technique used for this study was structural equation modeling and it was conducted through SmartPLS3.0 software. This software performs amazingly with smaller sample sizes (Hair, Sarstedt, Hopkins, \& Kuppelwieser, 2014). The two significant stages of this analysis are the measurement modeling and the structural modeling.

\section{Reliability and Validity of the Instrument}

After the model was constructed, firstly the measurement model was tested with the help of PLS algorithm. It was required for evaluating the reliability, validity and the model fitness. Initially, the factor loadings of the items of different variables were seen and those which were less than 0.65 were removed (Birkinshaw, Morrison, \& Hulland, 1995). After that a new model was built which only consisted of the items that had the loadings of 0.65 and above. As noted earlier, out of four variables, three were multi-dimensional and only employee resilience was a unidimensional construct. Thus employee resilience was deemed as reflective construct and the other variables were treated as 2 nd order formative constructs. The item loadings for all items for all the dimensions of all the constructs were at least 0.65 and above. After verifying the loadings of all the items, the multi-dimensional variables were converted to 2 nd order formative constructs and their latent variable scores were used in the structural model. The validity and reliability tests for all constructs were found satisfactory before proceeding for further analysis.

The reliability of the constructs is asserted through the values of Cronbach alpha and composite reliability. Reliability of any construct is deemed fine if the Cronbach alpha's values are 0.7 and above (Raghu \& Rodrigues, 2021). Additionally, it's considered suitable if the composite reliability is ranging between 0.7 to 0.9 (Taber, 2018). Secondly, the convergent validity of all constructs is verified through the values of AVE (Average Variance Extracted) and values of outer loadings. The values of (AVE) are required to be higher than 0.5 (Hair et al., 2014). The reliability and the convergent validity of all the constructs were conveniently established because the Cronbach alpha's values were more than 0.7 and composite reliabilities were falling in the range of 0.7 to 0.9 and the values of AVE were greater than 0.5. Lastly, most of the outer loading of all the constructs were greater than 0.65 .

There are multiple ways for establishing the discriminant validity of a construct but this study analyzed HTMT ratios to ascertain the discriminant validity of its constructs. Ideally, the values of HTMT ratios should be less than 0.1 (Garson, 2016). As displayed by the table 1, HTMT ratios of all constructs are less than 0.1 and support the claims of discriminant validity.

Table 1: HTMT ratios

\begin{tabular}{lcccc}
\hline & $\begin{array}{l}\text { Employee } \\
\text { Resilience }\end{array}$ & $\begin{array}{l}\text { Empowering } \\
\text { Leadership }\end{array}$ & $\begin{array}{l}\text { Psychological } \\
\text { Empowerment }\end{array}$ & $\begin{array}{l}\text { Work } \\
\text { Engagement }\end{array}$ \\
$\begin{array}{l}\text { Employee } \\
\text { Resilience }\end{array}$ & --- & & & \\
$\begin{array}{l}\text { Empowering } \\
\text { Leadership }\end{array}$ & 0.843 & --- & & \\
$\begin{array}{l}\text { Psychological } \\
\text { Empowerment }\end{array}$ & 0.853 & 0.826 & -- & \\
Work Engagement & 0.901 & 0.804 & 0.827 & --- \\
\hline
\end{tabular}

A model's fitness is evaluated through the SRMR values which should be lesser than 0.08 if the model has to be declared fit (Raghu \& Rodrigues, 2021). The value of SRMR was 0.044 so the model was pronounced fit for testing. Besides this, NFI values were checked which should be closer to 1 if the model is to be deemed fit (Smith \& McMillan, 2001); and here the value was 0.88 which further corroborated model fitness.

\section{Structural Model}


A structural model was created after obtaining satisfying results from the calculations of the measurement model. It helped to test the hypotheses previously stated in the literature review. As suggested by Bergh et al. (2016), the structural model is needed for probing the indirect/direct effects as well as for doing mediation analysis. The hypotheses were tested using the bootstrapping procedure with a sub sample of 1000. It was carried out through a one-tailed hypotheses test and analyzed that whether a hypothesis was significant or not. The bootstrapping process supplied the p-values, t-values and the path coefficients of the different variables included in the research. The structural model is illustrated in figure 2.

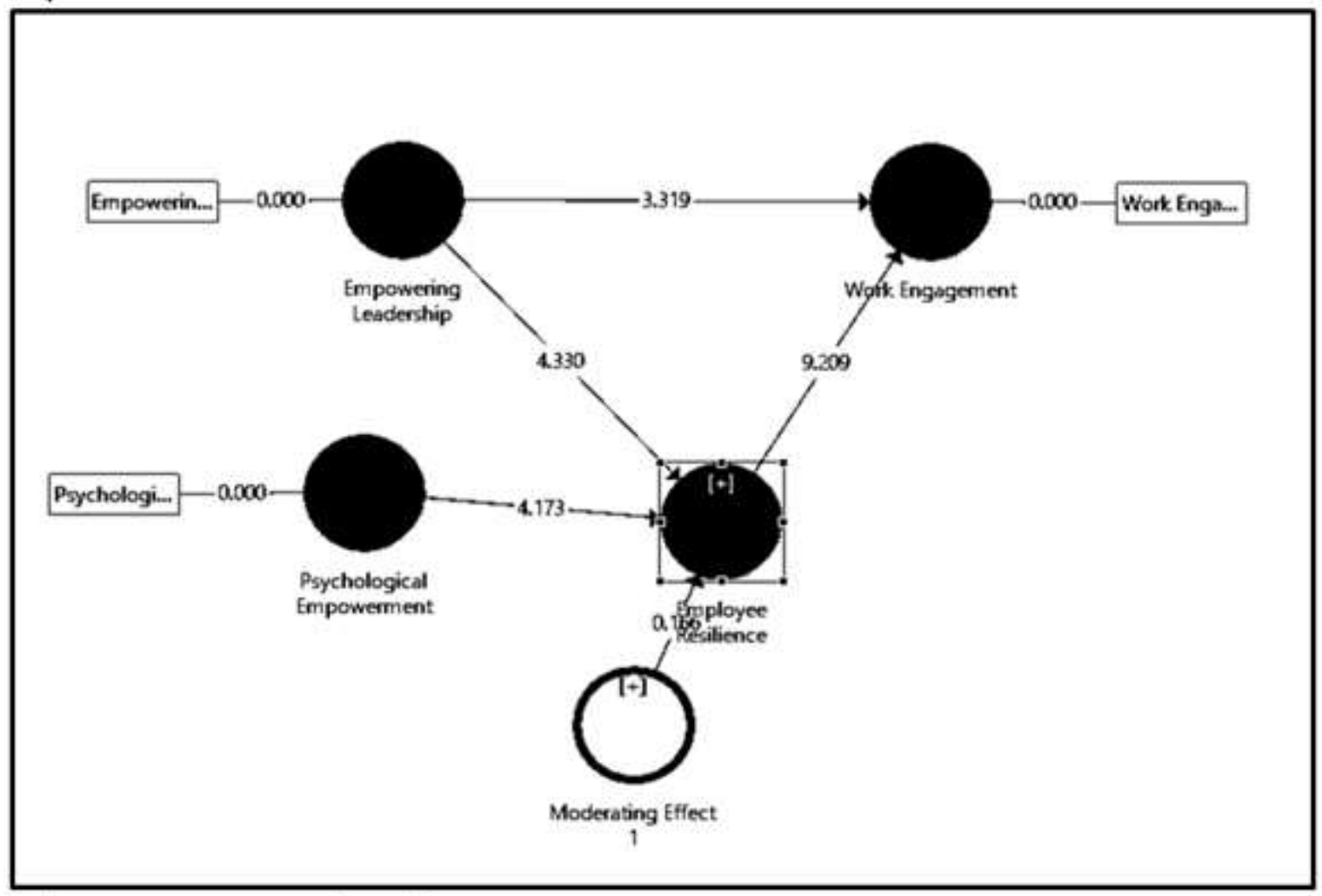

Figure 2: Structural Model

\section{Results of Hypotheses Tests}

For mediation tests, recommendation of Baron and Kenny were followed (1986). Thus, before constructing the full model, empowering leadership and work engagement were only placed to evaluate the direct association among the two. The results deemed the relationship significant so H1 was accepted. After that, a mediator (employee resilience) was added and then the impact of empowering leadership on work engagement was again checked and it also came out to be significant having $\mathrm{p}$-value $=0.000$ and $\mathrm{t}$-value $=5.824$ (Table 2). Moreover, positive coefficient's (0.534) value substantiated a positive impact of empowering leadership on work engagement. Secondly, the impact of empowering leadership on employee resilience was examined and it also turned out to be significant positive with a p-value of 0.000 , t-value of 4.20 , and coefficient as 0.424. Thus, H2 was also accepted. Thirdly, the relationship between employee resilience and work engagement was probed and it was also declared significant ( $\mathrm{p}$ - value $=0.000$, tvalue $=9.260$, coefficient $=0.679$ ). So, H3 was also supported. Thirdly, the mediating role of employee resilience was investigated and this was also proved significant as again the findings provided p-value $=0.000, \mathrm{t}$-value $=4.383$ and positive coefficient as well $(0.288)($ Table 3$)$. Hence, $\mathrm{H} 4$ was accepted and it was confirmed that if organizations adopt empowering leadership then it will foster employee resilience which will trigger work engagement. The mediation effect was partial because the direct relationship between empowering leadership and work engagement was also significant. Lastly, the moderating effect of psychological empowerment was studied 
but it did not came out to be significant because the p-value of the test came out to be $0.576, \mathrm{t}$ value was 0.560 (Table 2). Thus, H5 was rejected and it was concluded that degree to which empowering leadership may instill employee resilience didn't depend on psychological empowerment.

Table 2: Findings of hypotheses tests (Direct Effects)

\begin{tabular}{|c|c|c|c|c|c|}
\hline \multirow[t]{2}{*}{ Paths } & \multirow[b]{2}{*}{ Coefficient } & \multirow[b]{2}{*}{ p-values } & \multirow[b]{2}{*}{ t-values } & \multicolumn{2}{|c|}{$\begin{array}{c}\text { Bias Corrected } \\
\text { Confidence Interval }\end{array}$} \\
\hline & & & & $2.5 \%$ & $97.5 \%$ \\
\hline $\mathbf{E L} \rightarrow \mathbf{W E}$ & 0.534 & 0.000 & 5.824 & 0.338 & 0.692 \\
\hline EL $\rightarrow$ ER & 0.424 & 0.000 & 4.200 & 0.222 & 0.613 \\
\hline $\mathbf{E R} \rightarrow \mathbf{W E}$ & 0.679 & 0.000 & 9.260 & 0.523 & 0.806 \\
\hline Mod effect1 $\rightarrow$ ER & 0.016 & 0.576 & 0.560 & -0.043 & 0.067 \\
\hline
\end{tabular}

Table 3: Findings of hypotheses tests (Indirect Effects)

\begin{tabular}{lccccc}
\hline Paths & \multicolumn{2}{c}{ Indirect Effects } & \multicolumn{2}{c}{ Bias Corrected Confidence } \\
& Coefficient & p-values & t-values & $\mathbf{2 . 5 . \%}$ & $\mathbf{9 7 . 5 \%}$ \\
\hline ER $\rightarrow$ EL $\rightarrow W E$ & 0.288 & 0.000 & 4.383 & 0.165 & 0.421 \\
\hline
\end{tabular}

As noted earlier, the values of coefficients for all the relations are positive so it can be concluded that all the relationships were positive. Specifically, when the levels of empowering leadership are high then it will escalate the levels of employee resilience which will consequently nurture increased work engagement.

\section{Discussion and Implications}

The results confirmed a positive relationship between empowering leadership and work engagement. It's already backed by previous studies. The studies conducted by Alotaibi et al. (2020) and Støren (2017) supported this relationship. Moreover, a research organized in Pakistan linked these two variables via organization justice perceptions (Kazi, Kazi, Kazi, \& Ahmedani, 2017). Although, the relationship has been studied in the past but in the context of a crisis the success of educational institutions could only be expounded by it because only empowering leadership would have fueled work engagement of their employees. Secondly, the findings supported a direct impact of empowering leadership on employee resilience which has been reported earlier (Nguyen et al., 2016). Development of employee resilience was imperative to succeed in pandemic because it would have helped the faculty members to show tenacity in these trying times. A study arranged in the telecommunication sector of Pakistan demonstrated that employee resilience could be instilled by a couple of HR practices (Khan et al., 2019). Thirdly, the positive relationship between employee resilience and work engagement was supported which has also been proven by prior studies (Dai, Zhuang, Huan, 2019; Malik \& Garg, 2017). Moreover, under these challenging circumstances employee resilience could be a fundamental prerequisite for work engagement because they would not have stayed committed to their work if they did not confront the situation with courage. Fourthly, the findings supported the mediating effect which showed that empowering leadership must have inculcated employee resilience which enabled them to stay indulged in their work. Lastly, the moderating effect was rejected so it was concluded that psychological empowerment didn't affect the level of resilience fostered by empowering leadership. It is to be highlighted that the moderating effect of psychological empowerment was rejected in a study that was conducted recently by Muniandi, Richardson, and Salamzadeh (2021) to investigate influence of ethical leadership on leader subordinate relationship amongst the women employees of the multinational enterprises of Malaysia. Hence, the findings of this research are in line with the extant research. 
The relationships proposed in this study are adequately supported through the theories mentioned in the literature review section. According to the Job demand Resource Model (Bakker \& Demerouti, 2017), job and personal resources are critical to development of work engagement. Therefore, empowering leadership which is classified as an important job resource (Støren, 2017) and employee resilience which is categorically identified as a personal resource (Paek et al., 2015) can foster greater work engagement in employees. Moreover, according the COR (Hobfoll, 2001) the existence of one resource will foster the search and acquisition of the other resource, so therefore, drawing upon this phenomenon, it is confirmed that empowering leadership can generate employee resilience which would enhance work engagement. Lastly, broaden and build theory posits that great experiences may elicit healthy emotions which can lead to the cultivation of multiple types of resources. Since empowering leadership guarantees sufficient freedom which is likely to trigger wonderful experiences that will evoke positive emotions thereby leading to the development of employee resilience which will ultimately escalate the levels of work engagement.

The study discovered that employee resilience is a mechanisms which the help of which empowering leadership improves and enhances employee work engagement. Moreover, it acknowledged the success garnered by private schools of Pakistan during the pandemic. Additionally, it provides a couple of suggestions too. It stresses the public schools of the country to follow the same route to maintain normalcy in turbulent times. It further recommends that organizations should take concrete steps to cultivate employee resilience to confront situations like Covid-19 pandemic. They can develop it if they select leadership whom they feel can work collaboratively and break traditional hierarchies.

\section{Limitations and Future Directions}

The data could only be gathered from Multan and nearby regions because travel was considerably interrupted. It was a quantitative study because of the shortage of time and a more thorough analysis of the situation would be presented by a qualitative study. The research paves the way for future studies. Researchers can study the effects of a different kind of leadership style such as spiritual leadership on employee resilience and similar studies can be conducted in other provinces where the moderating effect of Psychological empowerment may be proven. Moreover, studies like these can be arranged in other industrial sectors to investigate how did they cope with a huge crisis.

\section{References}

Ahmed, F., Zviedrite, N., \& Uzicanin, A. (2018). Effectiveness of workplace social distancing measures in reducing influenza transmission: A systematic review. BMC Public Health, 18(1), 1-13.

Ahearne, M., Mathieu, J., \& Rapp, A. (2005). To empower or not to empower your sales force? An empirical examination of the influence of leadership empowerment behavior on customer satisfaction and performance. Journal of Applied psychology, 90(5), 945-955.

Alotaibi, S. M., Amin, M., \& Winterton, J. (2020). Does emotional intelligence and empowering leadership affect psychological empowerment and work engagement. Leadership \& Organization Development Journal, 18(1), 1-13.

Arnold, J. A., Arad, S., Rhoades, J. A., \& Drasgow, F. (2000). The empowering leadership questionnaire: The construction and validation of a new scale for measuring leader behaviors. Journal of Organizational behavior, 21(3), 249-269.

Atalan, A. (2020). Is the lockdown important to prevent the COVID-19 pandemic? Effects on psychology, environment and economy-perspective. Annals of Medicine and Surgery, 56, 38-42.

Bakker, A. B., \& Demerouti, E. (2017). Job demands-resources theory: Taking stock and looking 
forward. Journal of Occupational Health Psychology, 22(3), 273-285.

Baron, R. M., \& David, A. K. (1986). Moderator-mediator variables distinction in social psychological research: Conceptual, strategic, and statistical considerations. Journal of Personality and Social Psychology, 51(6), 1173-82.

Bergh, D. D., Aguinis, H., Heavey, C., Ketchen, D. J., Boyd, B. K., Su, P., ... \& Joo, H. (2016). Using meta-analytic structural equation modeling to advance strategic management research: Guidelines and an empirical illustration via the strategic leadership-performance relationship. Strategic Management Journal, 37(3), 477-497.

Birkinshaw, J., Morrison, A., \& Hulland, J. (1995). Structural and competitive determinants of a global integration strategy. Strategic Management Journal, 16(8), 637-655.

Breevaart, K., \& Bakker, A. B. (2018). Daily job demands and employee work engagement: The role of daily transformational leadership behavior. Journal of Occupational Health Psychology, 23(3), 338-349.

Cai, D., Cai, Y., Sun, Y., \& Ma, J. (2018). Linking empowering leadership and employee work engagement: The effects of person-job fit, person-group fit, and proactive personality. Frontiers in Psychology, 9, 1304.

Cooper, B., Wang, J., Bartram, T., \& Cooke, F. L. (2019). Well-being-oriented human resource management practices and employee performance in the Chinese banking sector: The role of social climate and resilience. Human Resource Management, 58(1), 85-97.

Cucinotta, D., \& Vanelli, M. (2020). WHO declares COVID-19 a pandemic. Acta BioMedica: Atenei Parmensis, 91(1), 157-160.

Dai, Y. D., Zhuang, W. L., \& Huan, T. C. (2019). Engage or quit? The moderating role of abusive supervision between resilience, intention to leave and work engagement. Tourism Management, 70, 69-77.

De Klerk, S., \& Stander, M. W. (2014). Leadership empowerment behaviour, work engagement and turnover intention: The role of psychological empowerment. Journal of Positive Management, 5(3), 28-45.

Dhawan, S. (2020). Online learning: A panacea in the time of COVID-19 crisis. Journal of Educational Technology Systems, 49(1), 5-22.

Fernandez, A. A., \& Shaw, G. P. (2020). Academic leadership in a time of crisis: The Coronavirus and COVID-19. Journal of Leadership Studies, 14(1), 39-45.

Franken, E., Plimmer, G., \& Malinen, S. (2020). Paradoxical leadership in public sector organisations: Its role in fostering employee resilience. Australian Journal of Public Administration, 79(1), 93-110.

Fredrickson, B. L. (2001). The role of positive emotions in positive psychology: The broadenand-build theory of positive emotions. American Psychologist, 56(3), 218-226.

Garson, G.D. (2016). Partial least squares: Regression \& structural equation models. USA: Statistical Publishing Associates.

Hair Jr., J. F., Sarstedt, M., Hopkins, L., \& Kuppelwieser, V. G. (2014). Partial least squares structural equation modeling (PLS-SEM): An emerging tool in business research. European Business Review, 26(2), 106-121.

Hart, O. E., \& Halden, R. U. (2020). Computational analysis of SARS-CoV-2/COVID-19 surveillance by wastewater-based epidemiology locally and globally: Feasibility, economy, opportunities and challenges. Science of the Total Environment, 730, 1-9.

Hobfoll, S. E. (2001). The influence of culture, community, and the nested-self in the stress process: Advancing conservation of resources theory. Applied psychology, 50(3), 337421.

Hobfoll, S. E., Halbesleben, J., Neveu, J. P., \& Westman, M. (2018). Conservation of resources in the organizational context: The reality of resources and their consequences. Annual Review of Organizational Psychology and Organizational Behavior, 5, 103-128.

Hodliffe, M. C. (2014). The development and validation of the employee resilience scale (EmpRes): The conceptualisation of a new model. (Master Dissertation). University of 
Canterbury, New Zealand.

Hu, Y., Zhu, L., Zhou, M., Li, J., Maguire, P., Sun, H., \& Wang, D. (2018). Exploring the influence of ethical leadership on voice behavior: How leader-member exchange, psychological safety and psychological empowerment influence employees' willingness to speak out. Frontiers in psychology, 9, 1718.

Hui, L., Qun, W., Nazir, S., Mengyu, Z., Asadullah, M. A., \& Khadim, S. (2020). Organizational identification perceptions and millennials' creativity: Testing the mediating role of work engagement and the moderating role of work values. European Journal of Innovation Management, 24(5), 1653-1678.

Kazi, S., Kazi, H., Kazi, A. S., \& Ahmedani, M. M. (2017). To investigate impact of leader empowerment behavior on employee work engagement: Mediating role of organizational justice perceptions. International Journal of Multidisciplinary Research and Development, 4(5), 176-180.

Khan, Z., Rao-Nicholson, R., Akhtar, P., Tarba, S. Y., Ahammad, M. F., \& Vorley, T. (2019). The role of HR practices in developing employee resilience: A case study from the Pakistani telecommunications sector. The International Journal of Human Resource Management, 30(8), 1342-1369.

Kim, M., \& Beehr, T. A. (2017). Directing our own careers, but getting help from empowering leaders. Career Development International, 22(3), 300-317.

Kim, M., \& Beehr, T. A. (2020). Job crafting mediates how empowering leadership and employees' core self-evaluations predict favourable and unfavourable outcomes. European Journal of Work and Organizational Psychology, 29(1), 126-139.

Kundu, S. C., Kumar, S., \& Gahlawat, N. (2019). Empowering leadership and job performance: mediating role of psychological empowerment. Management Research Review, 42(5), 605-624.

Kuntz, J. R., Näswall, K., \& Malinen, S. (2016). Resilient employees in resilient organizations: Flourishing beyond adversity. Industrial and Organizational Psychology, 9(2), 456-462.

Lee, A., Willis, S., \& Tian, A. W. (2018). Empowering leadership: A meta-analytic examination of incremental contribution, mediation, and moderation. Journal of Organizational Behavior, 39(3), 306-325.

Lu, L., Lu, A. C. C., Gursoy, D., \& Neale, N. R. (2016). Work engagement, job satisfaction, and turnover intentions: A comparison between supervisors and line-level employees. International Journal of Contemporary Hospitality Management, 28(4), 737 761

Malik, P., \& Garg, P. (2017). Learning organization and work engagement: The mediating role of employee resilience. The International Journal of Human Resource Management, 31(8), 1071-1094.

Meng, L., Jin, Y., \& Guo, J. (2016). Mediating and/or moderating roles of psychological empowerment. Applied Nursing Research, 30, 104-110.

Muniandi, J., Richardson, C., \& Salamzadeh, Y. (2021). Ethical leadership and quality of leadersubordinate relationship among women working in multinational enterprises in Malaysia, moderating role of employee psychological empowerment. Gender in Management: An International Journal. ahead-of-print. https://doi.org/10.1108/GM-02-2021-0038

Nguyen, Q., Kuntz, J. R., Näswall, K., \& Malinen, S. (2016). Employee resilience and leadership styles: The moderating role of proactive personality and optimism. New Zealand Journal of Psychology (Online), 45(2), 13-21.

Ojo, A. O., Fawehinmi, O., \& Yusliza, M. Y. (2021). Examining the predictors of resilience and work engagement during the COVID-19 pandemic. Sustainability, 13(5), 2902.

Özarallı, N. (2015). Linking empowering leader to creativity: The moderating role of psychological (felt) empowerment. Procedia-Social and Behavioral Sciences, 181, 366376.

Paek, S., Schuckert, M., Kim, T. T., \& Lee, G. (2015). Why is hospitality employees' 
psychological capital important? The effects of psychological capital on work engagement and employee morale. International Journal of Hospitality Management, 50, 9-26.

Park, J. G., Kim, J. S., Yoon, S. W., \& Joo, B. K. (2017). The effects of empowering leadership on psychological well-being and job engagement: The mediating role of psychological capital. Leadership \& Organization Development Journal, 38(3), 350-367.

Qatrunnada, R. Z., \& Parahyanti, E. (2019, August). Empowering leadership and work engagement: The role of psychological empowerment as a mediator. In 2nd International Conference on Intervention and Applied Psychology (ICIAP 2018). Atlantis Press, 229, 954-964.

Raghu, S. J., \& Rodrigues, L. L. (2021). Developing and validating an instrument of antecedents of solid waste management behaviour using mixed methods procedure. Cogent Psychology, 8(1), 1886628.

Schaufeli, W. B., \& Bakker, A. B. (2004). Job demands, job resources, and their relationship with burnout and engagement: A multi-sample study. Journal of Organizational Behavior: The International Journal of Industrial, Occupational and Organizational Psychology and Behavior, 25(3), 293-315.

Schaufeli, W. B., Bakker, A. B., \& Salanova, M. (2006). The measurement of work engagement with a short questionnaire: A cross-national study. Educational and Psychological Measurement, 66(4), 701-716.

Schaufeli, W. B., \& Taris, T. W. (2014). A critical review of the job demands-resources model: Implications for improving work and health. In G.F. Bauer \& O. Hämmig (eds.), Bridging occupational, organizational and public health: A transdisciplinary approach (pp. 4368). Germany: Springer Science + Business Media Dordrecht.

Sekaran, U. (2003). Research methods for business: A skill-building approach (4th Edition). NY: John Wiley \& Sons.

Smith, T. D., \& McMillan, B. F. (2001, February). A primer of model fit indices in structural equation modeling. Paper presented at the Annual Meeting of the Southwest Educational Research Association, New Orleans, LA.

Spreitzer, G. M. (1995). Psychological empowerment in the workplace: Dimensions, measurement, and validation. Academy of Management Journal, 38(5), 1442-1465.

Støren, K. S. (2017). Exploring the dynamics of work engagement with empowering leadership as predictor: A longitudinal multi-level approach. (Master's thesis). University of Oslo, Norway.

Taber, K. S. (2018). The use of Cronbach's alpha when developing and reporting research instruments in science education. Research in Science Education, 48(6), 1273-1296.

Thun, S., \& Bakker, A. B. (2018). Empowering leadership and job crafting: The role of employee optimism. Stress and Health, 34(4), 573-581.

Turner, P. (2019). Employee engagement in contemporary organizations: Maintaining high productivity and sustained competitiveness. Switzerland: Springer Nature.

Toquero, C. M. (2020). Challenges and opportunities for higher education amid the COVID-19 pandemic: The Philippine context. Pedagogical Research, 5(4), 1-5. 